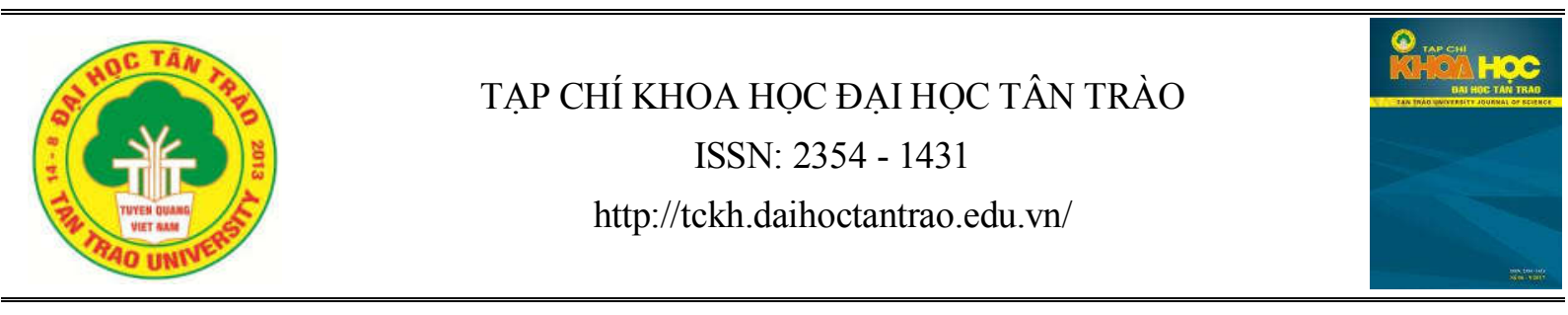

\title{
Một số chiến lược từ chối trực tiếp lời mời của người Mỹ
}

Phạm Tuấn Doanh ${ }^{a}$

${ }^{a}$ Học viện hành chính quốc gia

Thông tin bài viết

Ngày nhận bài:

$15 / 3 / 2019$

Ngày duyệt đăng:

$10 / 6 / 2019$

Tù khóa:

Hành vi tù̀ chối; chiến luợc tù chối; lời mòiz; chiến lược tù chối trực tiếp; hành vi tù chối lời mời

\section{Tóm tắt}

Hành vi từ chối, giống như các hành vi khác, xuất hiện ở tất cả các ngôn ngữ. Nó được dùng để biểu thị sự không chấp nhận một thay đổi nào đó theo hướng đã được đề xuất (như yêu cầu, đề nghị, mời rủ, gợi ý ...) trong quan hệ giao tiếp hội thoại. Dưới sự tác động của một số nhân tố như vị thế xã hội, giới tính, tuổi tác..., khi từ chối lời mời, người Mỹ có thể lựa chọn chiến lược từ chối trực tiếp hay chiến lược từ chối gián tiếp. Trong bài viết này, tác giả trình bày một cách giản lược về những kết quả mà chúng tôi đã thu được khi nghiên cứu về các chiến lược từ chối trực tiếp lời mời thường dùng $\mathrm{c}$ ủa người Mỹ.

\section{Mở đầu}

Hành vi từ chối theo Brown và Levinson (1978) là một hành vi đe doạ thể diện điển hình. Vì hành vi từ chối biểu thị ý chí của bản thân người nói không tiếp nhận, từ chối lời mời của người nghe làm tổn hại đến tính hợp tác giữa người nói và người nghe nên đe doạ thể diện dương tính (xâm phạm nguyện vọng muốn được người khác tiếp nhận, ưa thích). Dó đó, người từ chối phải điều chỉnh bằng những quan hệ và cách thức khác nhau ở các cộng động có nền văn hoá khác nhau. Hành vi từ chối diễn ra khi người nói trực tiếp hoặc gián tiếp từ chối một lời mời. Trong bài viết này, tác giả trình bày các chiến lược từ chối trực tiếp lời mời được người Mỹ ưa dùng có trong 21 tác phẩm văn học Mỹ và một số bộ phim Mỹ được phát sóng trên đài truyền hình Việt Nam. Bài báo này giúp cho người đọc có cái nhìn rõ hơn về sự tương đồng và khác biệt giữa người Mỹ và người Việt khi sử dụng các chiến lược từ chối trực tiếp lời mời.

\section{Hành vi mời, hành vi từ chối lời mời và hành vi từ chối trực tiếp lời mời}

\subsection{Hành vi mò̀i}

Lời mời là lời nói thể hiện thái độ thân thiện, lịch sự, tôn kính và mến khách của người nói và xuất phát từ lợi ích của cả người nói lẫn người nghe. Theo từ điển Oxford Wordpower (2003, 366), invite is a verb which means "to ask somebody to come somewhere or to do something)" (Động từ mò̀i có nghĩa là mời ai đó đi đâu hoặc mời ai đó làm gì) (tác giả dịch). Theo Từ điển tiếng Việt do Hoàng Phê chủ biên (2006, 645), hành động mời là “1. Tỏ ý mong muốn, yêu cầu người khác làm việc gì một cách lịch sự, trân trọng. Mời anh đến chơi. Đưa tay mời ngồi. Kính mòi. Giấy mòi họp. Mời cơm thân mật (trang trọng: mời ăn cơm). 2. Ăn hoặc uống (nói về người đối thoại một cách lịch sự). Anh mời nước đi. Các bác đã mòi cơm chua". Như vậy, mục đích của hành động mời là hướng tới hành động tương lai của người nghe. Khi sử dụng động từ mời, người nói thường hạ thấp mình một chút, nhún nhường để tỏ ra lịch sự mặc dù vị thế xã hội cao hơn, ngang bằng hay thấp đều có thể sử dụng được nó. Theo phân loại hành vi ngôn ngữ của Searle (1969) thì hành vi mời thuộc nhóm Điều khiến (Directives). Trong đó, đích ở lời là đặt người nghe $(\mathrm{H})$ vào trách nhiệm thực hiện một hành động nào đó trong tương lai; Hướng khớp ghép là hiện thực- lời; Trạng thái tâm lý là sự mong muốn của người nói $(\mathrm{S})$; Nội dung mệnh đề là hành động tương lai của người nghe $(\mathrm{H})$.

\subsection{Hành vi tù̀ chối lò̀i mò̀i}

Theo từ điển Oxford Wordpower (2003, 551), "Refusing an invitation means you are not willing or reject to do something when someone invites you to do. 
It also means you don't accept the invitation of someone" (từ chối một lời mời có nghĩa là bạn không sẵn sàng hoặc từ chối thực hiện lời mời nào đó. Nó cũng có nghĩa là bạn không chấp nhận lời mời của một ai đó) (tác giả dịch). Như vậy, có thể thấy hành vi tù̀ chối một lời mời là "nói với nguời mời là không nhận điều gì hay không làm điều gì được đề cập đến trong lòi mòi."

2.3. Hành vi tù chối trục tiếp lời mời là hành vi mà người nghe có thể nhận diện ra đích tại lời nhờ vào các câu chữ biểu thị chúng mà không cần phải suy ý, không cần dựa vào ngữ cảnh. Dựa vào hệ thống phân loại của Beebe và các cộng sự của ông (1990), hành vi từ chối trực tiếp lời mời thường được biểu thị bằng động từ ngữ vi (ĐTNV), ví dụ: (I refuse- Tôi từ chối), từ phủ định No (không), never (không bao giờ), cách nói phủ định (I can't-Tôi không thể)... Dưới đây là một số chiến lược từ chối trực tiếp lời mời thường dùng của người Mỹ.

3. Một số chiến lược từ chối trực tiếp lời mời được người Mỹ thường dùng

\subsection{Chiến lực từ chối thẳng}

Đây là chiến lược biểu thị ý từ chối dứt khoát, ít nhiều có nguy cơ đe dọa đến thể diện. Chiến lược này thường được sử dụng khi người từ chối có địa vị cao hơn hoặc ngang bằng người mời. Hành vi từ chối thẳng thừng được thực hiện thông qua một số các phương tiện biểu đạt sau:

\section{a. Biểu thức ngũ vi chứa động tù̀ ngũ vi (ĐTNV)}

Động từ biểu thị hành vi từ chối (HVTC) trong tiếng Anh Mỹ bao gồm các động từ: refuse (từ chối), resist (cự tuyệt).... nhằm thực hiện hành vi không chấp nhận, bác bỏ một cách tường minh trong tiếng Anh. Thực tế cho thấy, rất ít khi người ta sử dụng ĐTNV này để biểu đạt lời từ chối.

Ví dụ 1: Cuộc thoại giữa Alex và Annie khi cô đến nhà chơi

\section{Alex: Cake? Biscuit? All homemade!}

(Em ăn bánh ngọt nhé? Bánh quy nhé? Tất cả đều của nhà làm.)

Annie: Oh, very nice. I'm sure. But I'll have to refuse. I'll be putting on pounds.

(Ồ, em chắc là đồ ăn sẽ rất ngon đấy. Nhưng em sẽ phải từ chối. Em đang tăng cân đây.) (Anderson, 1996, tr.285)

Annie đã từ chối trực tiếp lời mời của người bạn Alex bằng việc sử dụng động từ ngữ vi "refuse".
Ví dụ 2: Cuộc thoại giữa Frankland và bác sỹ Watson tại nhà Frankland

Frankland: You'll help me to empty the decanter in honour of this great occasion!

(Lẽ nào ngài không cùng tôi nốc hết bình rượu để chào mừng sự kiện đáng vui này hay sao?)

Watson: I resist all your solicitations...

(Tôi từ chối lời mời nốc nốt rượu ...) (Doyle, 1986, tr.637)

Trong ví dụ trên, bác sỹ Watson sử dụng động từ resist để mô tả hành động từ chối dứt khoát lời mời, bất chấp vị thế xã hội giữa hai người như thế nào.

\section{b. Biểu thức ngũ vi chúa tù phủ định NO - KHÔNG}

Từ này thường xuất hiện trong đoạn thoại như là một dấu hiệu nhận biết cho HVTC xuất hiện. Khi phát ngôn được bắt đầu được nói, từ này có giá trị thu hút người nghe, ban đầu nó biểu đạt một hành vi dường như là sự bác bỏ, nhưng ngay sau đó là HVTC xuất hiện nhằm giải thích cho việc bác bỏ vừa nói ra.

Ví dụ 3: Cuộc thoại giữa bác sỹ Judd và bệnh nhân nữ tại phòng khám

Judd: Would you like some water? (Cô uống chút nước nhé?)

Bệnh nhân nữ: No no! I'm f-fine. (Kh...Không! em kh...khoẻ mà bác sĩ.) (Sheldon, 1985b, tr.64)

Bệnh nhân nữ đã từ chối thẳng thừng lời mời của bác sỹ Judd bằng từ "No" và kèm với lời giải thích "I'm f-fine" (em kh...khoẻ mà bác sĩ).

Ví dụ 4: Cuộc thoại giữa hai vợ chồng Tracy và Jeff tại phòng ăn

Tracy: Sweet roll, Jeff? Coffee? (Anh ăn bánh ngọt, cà phê nhé, Jeff?)

Jeff: No, thanks. (Không, cảm ơn em.) (Sheldon, 1985a, tr.386)

Jeff từ chối lời mời của vợ bằng từ "No" và đi kèm lời cảm ơn.

\section{c. Biểu thức ngũ vi chúa tù phủ định NOT}

NOT (N'T) đứng ngay sau trợ động từ do/ does/ hoặc sau động từ $\mathrm{BE}$ và có thể hình thành dạng thức đầy đủ

$$
\mathrm{S}+\mathrm{do} / \text { does } /+\mathrm{NOT}+\mathrm{V} \text { hoặc } \mathrm{S}+\mathrm{BE}+\mathrm{NOT}+\ldots
$$

Ví dụ 111: Cuộc thoại giữa Lara và diễn viên Phillip Adler sau khi tan buổi biểu diễn ở nhà hát

Lara: If you're free tomorrow, Mr. Adler, I'm having an intimate little dinner at my villa. Very intimate. 
(Nếu ngày mai ông rảnh, thưa ông Phillip Adler, em mời ông đến dự bữa ăn ở biệt thự của em. Một bữa ăn rất thân tình.)

Philip: Thank you, but I'm afraid I'm not free.

(Cảm ơn cô... nhưng tôi e không được rảnh.) (Sheldon, 1995b, tr.342)

Ví dụ 5: Cuộc thoại giữa Dana và David Haynes khi ông đang trên đường đưa Dana từ sân bay về khách sạn nhân dịp lần đầu cô sang Brussels công tác

David Haynes: If you're free this evening, I'd like -

(Nếu chiều nay cô rảnh, tôi muốn...)

Dana: I'm sorry. I'm afraid I'm not. (Xin lỗi. Tôi e là không.) (Sheldon, 2001, tr.136)

d. Biểu thức ngũu vi chứa tù phủ định cấu tạo bằng thêm tiền tố hoặc hậu tố

Những từ phủ định mới được cấu tạo bằng cách là thêm tiền tố hoặc hậu tố vào sau các căn tố mang nghĩa phủ định như: UN-, IM-, DIS, IN-, -LESS, ... Hình thức này được gọi là cấu tạo hình thái học.

Ví dụ 6: Cuộc thoại giữa bà Benecke và giám đốc điều hành Gregory Halston tại một cửa hiệu)

Benecke: You gotta come up and have tea with us some afternoon. You'll love old P.J.

(Một chiều nào đó, anh phải tới uống trà với chúng tôi nhé. Anh sẽ rất khoái ông $\mathrm{P} . J$ của tôi cho mà xem.)

Gregory Halston: I am sure I would. Unfortunately, I work afternoons. Too bad.

(Thật tình tôi muốn có được vinh hạnh đó. Nhung đáng tiếc, tôi đều phải làm việc các buổi chiều. Thật chán chết.) (Sheldon, 1985a, tr.232)

Trong tình huống trên, giám đốc điều hành Gregory Halston đã từ chối thẳng thừng lời mời của bà Benecke “Unfortunately”(Nhưng đáng tiếc), nhưng cũng đưa ra lý do "I work afternoons" (tôi đều phải làm việc các buổi chiều.) để làm giảm nhẹ sự đe dọa thể diện cho người mời.

c. Biểu thức ngũ vi chứa tù phủ định NOT đi kèm vói thành phần mở rộng bày tỏ sụ đồng tình

Ví dụ 7: John nói với anh bạn học cùng

Mark: How about going to a disco tonight? (Tối nay đi vũ trường nhé?)

Anh bạn: I'd love to, but I can't. I've got to do some homework.

(Tớ thích lắm, nhưng tớ không thể đi được. Tớ phải làm bài tập về nhà.) (John, 2000, tr.43)
Người bạn của Mark đưa ra lời từ chối bằng việc thể hiện sự đồng tình, thiện chí muốn thực hiện lời mời của Mark "I'd love to" (Tớ thích lắm), song vì lí do "I’ve got to do some homework" (nhưng tớ phải làm bài tập về nhà.) mà không thể nhận lời mời được.

\subsection{Chiến lực tù̀ chối kèm nhã ngũ}

Đây là một chiến lược sử dụng một số yếu tố có tính xưng hô thận trọng, tỏ ý xin lỗi, đáng tiếc ... Chiến lược này thường xuất hiện một số biểu thức ngữ vi như: I'm sorry (Tôi xin lỗi); I'm afraid I can't (Tôi e rằng tôi không thể); That's very kind of you (Bạn thật tốt), How kind of you (Bạn tốt quá) ....

Ví dụ 8: Cuộc thoại giữa hai người bạn Susan và Hale tại văn phòng

Susan: Could you come to tea on Tuesday?

(Thứ ba này mời cậu qua chỗ mình uống trà nhé.)

Hale: That's very kind of you but I'm afraid I'm rather tied up. You see

(Cậu tốt quá nhưng mình sợ là mình khá bận. Cậu thấy đấy) (Sheldon, 1999a, tr.172)

Ví dụ 9: Cuộc thoại giữa Pamela và cô bạn đồng nghiệp Dana qua điện thoại

Pamela: Hello, Dana. I know this is sudden, but a good friend has just come to town and Roger and I are giving him a little party next Wednesday. I know Jeff is still out of town, but we would love to have you come. Are you free?

(Chào Dana. Tôi biết là hơi bất ngờ nhưng chúng tôi có vài người bạn tốt ở xa đến thăm và Roger cùng tôi dự định tổ chức một bữa tiệc nhỏ vào thứ tư tới. Tôi biết Jeff vẫn còn đang ở xa, nhưng tôi rất mong sự có mặt của cô. Cô có rảnh không?)

Dana: I'm afraid I'm not. I'm leaving for Dusseldorf tonight.

(Tôi e là không được rồi. Đêm nay tôi sẽ đi Dusseldorf.) (Sheldon, 2001, tr.124)

Trong số 409 lời từ chối trực tiếp của người Mỹ mà tác giả thu thập được, có 89/409 đoạn thoại từ chối mà người Mỹ sử dụng từ "I'm sorry" + biểu thức ngữ vi từ chối.

Ví dụ 10: Jeff gọi điện thoại mời hai cô bạn đi ăn tối

Jeff: Why don't we all have dinner together to celebrate?

(Sao chúng ta không cùng ăn tối để chúc mừng nhau nhi?) 
Gunther: I can't. I'm sorry, but I have a previous engagement.

(Tôi không đi được. Rất tiếc, nhưng tôi mắc hẹn mất rồi.)

(Sheldon, 1985a, tr.337)

Với mối quan hệ thân tình, Gunther bày tỏ từ chối trực tiếp lời mời của Jeff "I can't”, kèm theo sự hối tiếc "I'm sorry" và lý do "I have a previous engagement" cũng là giảm thiểu đe dọa thể diện cho người mời.

Trong mọi ngôn ngữ thì lời cảm ơn luôn là phương tiện biểu đạt tính lịch sự một cách chuẩn mực nhất. Đối với lời mời thì việc sử dụng lời cảm ơn trong lời đáp như có tính chất khuôn mẫu.

Ví dụ 11: Cuộc thoại giữa hai đồng nghiệp Will và Clark trên máy bay

Will: Want a drink, Clark? (Uống chút gì nhé Clark?) Clark: No. Thank you.(Không. Cảm ơn.) (Moyes, 2012, tr.284)

Ví dụ 12: Cuộc thoại giữa hai người bạn ở trường

SP1: I'm going to the park with some friends for a barbecue on Sunday. Would you like to join us?

(Tao sẽ đến công viên dự một bữa ăn ngoài trời với vài nhỏ bạn vào chủ nhật. Mày có muốn tham gia không?

SP2: Thanks, but unfortunately I have to take my sister to the airport on Sunday.

(Cám ơn, nhưng xui xẻo là chủ nhật tao phải đưa chị tao lên sân bay.) (Richards, J. C., Hull, J. and Protor S., 2004, tr.133)

Trong hai ví dụ trên, Clark (ví dụ 11) và Sp2 (ví dụ 12) đều đưa ra lời cảm ơn "Thank you./thanks"người mời khi đưa ra lời từ chối. Điều này đã giúp cho giảm thiểu mức độ đe dọa thể diện đối với người tham thoại, đồng thời nó cũng cho thấy mong muốn hòa đồng của người nói đối với người nghe, giúp cho không khí giao tiếp bớt căng thẳng.

Ví dụ 13: Cuộc thoại giữa chị giúp việc Bessie với Jane bên giường bệnh

Bessie: Would you like to drink, or could you eat anything?

(Cô có muốn uống nước hoặc có thể ăn một chút gì không?)

Jane: No, thank you, Bessie. (Không, cảm ơn chị Bessie.) (Bronte, 2003, tr.30)
Jane đưa ra lời từ chối dứt khoát kèm sử dụng nhã ngữ "thank you" (cảm ơn chị) biểu thị sự tế nhị, giảm bớt sự đe dọa thể diện của chị Bessie.

\subsection{Chiến lự̛c từ chối bằng cách phủ nhận} khả năng

Chiến lược này có thể phân tích theo định hướng thể hiện âm tính, tự chê trách, hành vi có tính cứu vãn thể diện đối ngôn giao tiếp. Đây là một chiến lược khá khôn ngoan vì bằng cách sử dụng chiến lược này, người từ chối đã chuyển trách nhiệm sang cho người mời.

Ví dụ 14: Cuộc thoại giữa Alex và người yêu tại một buổi khiêu vũ

Alex: Say, we've come here to dance but not to sit and listen. Why not have a dance?

(Em này, chúng mình đến đây để khiêu vũ chứ đâu để ngồi và nghe. Sao không nhảy một bài nhỉ?)

Annie: You are right, dear. Sitting is boring, but I can't. I'm not good at Tango.

(Anh nói đúng, anh yêu. Ngồi không thật là chán, nhưng em không thể. Em lại không rành điệu Tango.) (Anderson, 1996, tr.229)

Annie từ chối lời mời của anh bạn trai bằng lối nói phủ nhận khả năng "I'm not good at Tango" (em lại không rành điệu Tango.). Trong trường hợp này, có vẻ như việc từ chối lời mời là do "lỗi”" của Alex. Anh đã mời Annie, người không biết khiêu vũ, chứ không phải là cô ấy không muốn thực hiện lời mời.

Ví dụ 15: Cuộc thoại giữa Pamela và cô bạn Dana qua điện thoại

Pamela: Roger and I are having a few people over for an early Christmas dinner tomorrow, and we want you and Kemal here. ....

(Tối mai tôi và Roger dự định mời vài người bạn đến dự bữa tiệc Giáng sinh sớm, chúng tôi mong rằng bạn và Kemal sẽ có mặt...)

Dana: No. As a matter of fact, I don't. (Không! Sự thực là không thể.) (Sheldon, 2001, tr.117)

Trong ví dụ trên, vị thế giữa Jean Pamela và Dana là ngang bằng. Jean Pamela đã đưa ra lời từ chối trực tiếp "No. As a matter of fact, I don't" (Sự thực là không thể.) rất quyết đoán và dứt khoát, ngôn từ đưa ra không có các yếu tố có nghĩa tình thái. Do vậy, ít nhiều có nguy cơ đe dọa đến thể diện của đối ngôn. 


\subsection{Chiến lược tù̀ chối bằng việc nêu tính vô ích của điều đự̆c mời}

Đây là chiến lược có tính đe dọa thể diện cao, thường được sử dụng khi người từ chối mời có vị thế xã hội cao hơn hoặc ngang bằng người mời. Nội dung thực sự của chiến lược này là lời từ chối được đưa ra xuất phát từ cơ sở đánh giá tính lợi/hại của hành vi được mời.

Ví dụ 16: Cuộc thoại giữa cô con gái và mẹ khi cô bê sữa đến bên giường

Cô con gái: Here, Mother, drink it. It will be good for you.

(Con mời mẹ, mẹ uống đi. Nó tốt cho sức khỏe của mẹ đấy ạ.)

Bà mẹ: I don't want to. I am not interested.

(Mẹ không muốn uống. Mẹ không thích) (Steinbeck, 2002, tr.174)

Trong ví dụ trên ta nhận thấy, bà mẹ đã từ chối bằng việc nêu tính vô ích của lời mời rằng “I don't want to.I am not interested" (Mẹ không muốn uống. Mẹ không thích).

\subsection{Chiến lược từ chối bằng cách trì hoãn}

Chiến lược này được xây dựng dựa trên yếu tố thời gian. Khi sử dụng chiến lược này, người nói bộc lộ ý muốn đẩy lùi thời hạn thực hiện một hành động mà người mời đưa ra. Một số cụm từ hay sử dụng gồm: not now (không phải bây giờ), not today (không phải hôm nay)...

Ví dụ 17: Cuộc thoại giữa hai người bạn tại quán cà phê

Dolly: Smoke? (Hút thuốc không?)

Anny: Not now. (Giờ thì không.) (Sheldon, 1985b, tr.95)

Ví dụ 18: Cuộc thoại giữa Alison Forbes Tipsy Barrett và cô con gái khi cô đến nhà thăm cha

Alison Forbes Tipsy Barrett: What about coffee? (uống cà phê nhé?)

Cô con gái: Not tonight, thank you, (Con cảm ơn, tối nay thì không) (Segal, 1970, tr.31)

Ví dụ 19: Cuộc thoại giữa Scarlett và cha đỡ đầu tại phòng khách

Scarlett: Drink this, Father, (Mời cha uống một chút a)

Cha đỡ đầu: But today I'm no, lady, and there is work to do tonight.
(Hôm nay thì không con ạ. Tối nay ta có nhiều việc phải làm) (Mitchell, 1999, tr.224)

Ở các ví dụ trên, người từ chối sử dụng một vài cụm từ khá điển hình như "not now" (Giờ thì không.); "not tonight/ But today I'm no" (tối nay thì không) ... để trì hoãn lời mời.

\subsection{Chiến lược tù̀ chối bằng cách nêu tính bất cập của điều được mò̀i}

Đây là chiến lược có nguy cơ đe dọa thể diện khá cao, đặc biệt trong trường hợp người từ chối chỉ ra sự bất cập như không hợp lý, quy định, nguyên tắc.... của lời mời hoặc sử dụng lối nói có tính hài hước, châm biếm...

Ví dụ 20: Cuộc thoại giữa người chồng và cô vợ đang mang bầu tại phòng khách gia đình

Mallory: How about a drink? (Em uống một chút gì nhé.)

Người vợ: No. I shouldn't. The baby...

(Không. Em không được uống. Hại đến con...) (Sheldon, 1995a, tr.220)

Ví dụ 21: Cuộc thoại giữa hai người chồng tên Jesse và người vợ đang mang bầu, Sandra tại bữa tiệc sinh nhật

Jesse: Come on in. Fix you a drink? (Nào, vào đi chứ? Uống cái gì nhé?)

Sandra: No, thanks. I don't want the baby to get into bad habits.

(Không, cảm ơn. Em không muốn con mình nhiễm thói xấu đó.) (Sheldon, 1999b, tr.176)

Trong hai ví dụ trên, cả hai người vợ đang mang thai nên đưa ra lời từ chối chỉ ra sự bất cập của việc uống rượu có thể làm ảnh hưởng đến con "The baby..." (Hại đến con...) hay "I don't want the baby to get into bad habits." (Tôi không muốn con mình nhiễm thói xấu đó.)

\subsection{Chiến lự̛c tù̀ chối bằng cách nêu lýdo}

Đây là chiến lược từ chối tế nhị, lịch sự, tránh gây tổn thương tinh thần cho người mời và mối quan hệ giữa những người tham thoại. Trong nhiều trường hợp, người từ chối có thể nêu ra các lý do khách quan hoặc chủ quan dẫn tới việc không thực hiện được lời mời.

Ví dụ 22: Cuộc thoại giữa cha Ralph và Harry khi ông đến nhà Harry đúng lúc cả nhà chuẩn bị ăn trưa

Harry: Father, will you eat with us? Corned beef and cabbage with boiled potatoes and parsley sauce, and for once the beef's not too salty. 
(Thưa cha, xin mời cha dùng cơm, có thịt bò nấu nhừ với khoai tây luộc, đặc biệt thịt bò không mặn lắm.)

Cha Ralph: No, Harry, I can't stay. ...

(Không, Harry, tôi không thể ở lại được.) (McCullough, 1977, tr.216)

Cha Ralph đã không ngần ngại khi đưa ra lời từ chối dứt khoát "No" (không) với con chiên của chúa kèm lý do (không thể ở lại được). Đó có thể là cái cớ để từ chối vì có thể cha Ralph không muốn ăn hoặc có thể ông đang cần phải đi đâu để xử lý công việc.

Ví dụ 23: Cuộc thoại giữa Clifton và Jill khi cô đến thăm vợ chồng Jill- Toby

Clifton: I want to give a dinner party for you and Toby. I'll take over the private room at the Bistro with a hundred of your most intimate friends. How does that sound?

(Tôi muốn có bữa tiệc mừng vợ chồng cô vào thứ bảy tuần sau tại nhà hàng Bistro với khoảng một trăm khách, đều là bạn bè thân thiết của hai người. Cô thấy được chứ?)

Jill: I'm so sorry. Cliff. I'm afraid I'm not going to be able to make it tonight. I'm a little tired. Toby thinks I should stay home and rest.

(Tiếc quá, Clif. Tôi sợ là tối nay sẽ không tới vui cùng ông được. Tôi hơi mệt, và Toby cho rằng tôi nên ở nhà nghỉ ngơi.) (Sheldon, 1976, tr.208)

Với lý do cá nhân "I'm a little tired." (Tôi hơi mệt,), Jill đã từ chối lời mời của ông Jill, vừa giảm bớt gây tổn thương tinh thần cho Jill vừa muốn thông báo mức độ mệt và giải pháp của mình "I should stay home and rest" (tôi nên ở nhà nghỉ ngơi.).

Ví dụ 24: Cuộc thoại giữa hai đồng nghiệp Terraglio và Alan tại trường quay

Terraglio: Here y'are. Wanna drop by for a little Christmas dinner? Stella'd love to see you.

(Tới chỗ bọn tớ dùng bữa vào đêm Noel chứ? Stella rất muốn được gặp cậu đấy.)

Alan: Can't. I'm spending Christmas with the wife and kids. I'm catching the next plane out to Florida.

(Tôi không thể! Tôi sẽ đón giáng sinh với vợ và các con. Tôi sẽ đáp chuyến bay sớm nhất đi Florida) (Sheldon, 1976, tr.170)

Ví dụ 25: Cuộc thoại giữa Pamela và cô bạn Dana qua điện thoại
Pamela: Hello, Dana. I know this is sudden, but a good friend has just come to town and Roger and I are giving him a little party next Wednesday. I know Jeff is still out of town, but we would love to have you come. Are you free?

(Chào Dana. Tôi biết là hơi bất ngờ nhưng chúng tôi có vài người bạn tốt ở xa đến thăm và Roger cùng tôi dự định tổ chức một bữa tiệc nhỏ vào thứ tư tới. Tôi biết Jeff vẫn còn đang ở xa, nhưng tôi rất mong sự có mặt của cô. Cô có rảnh không?

Dana: I'm afraid I'm not. I'm leaving for Dusseldorf tonight.

(Tôi e là không được rồi. Đêm nay tôi sẽ đi Dusseldorf.) (Sheldon, 2001, tr.124)

Ví dụ 26: Cuộc thoại giữa ông Billy với cô cháu gái khi cô đến thăm ông

Ông Billy: Can you stay for dinner?

(Cháu ở lại ăn tối cùng gia đình bác nhé!)

Cháu gái: No, I've got to feed Charlie, you know.

(Dạ không được đâu ạ, cháu còn phải về nấu ăn cho Charlie (bố cô gái) nữa, bác cũng biết rồi đấy.) (Meyer, 2006, tr.65)

Ở ví dụ 24, 25, 26, với những lý do khách quan như "I'm catching the next plane out to Florida." (Tôi sẽ đáp chuyến bay sớm nhất đi Florida) hay "I'm leaving for Dusseldorf tonight."(Đêm nay tôi sẽ đi Dusseldorf.) hay "I've got to feed Charlie"(cháu còn phải về nấu ăn cho Charlie (bố cô gái) nữa,), người được mời tế nhị từ chối lời mời, tránh làm mất thể diện cho người mời.

Có thể nói, chiến lược từ chối trực tiếp bằng cách nêu lý do là hình thức từ chối được ưa dùng do khi phải từ chối thì người từ chối thường phải viện đến một lý do để biện minh cho lời từ chối của mình. Người nghe cũng vì thế mà đồng ý, cảm thông chấp nhận cho hoàn cảnh thực tại của người từ chối.

Ví dụ 27: Cuộc thoại giữa Evenlyn và Catherine tại phòng làm việc

Evenlyn: "Miracle on Thirty-fourth Street" is playing at the Criterion. It's had great reviews. Would you like to see it tonight?

("Điều kỳ lạ ở phố Ba mươi tư" đang diễn ở rạp Criterion. Vở này đã được khen nhiều lắm. Tối nay cô đi xem phim với tôi nhé?)

Catherine: I can't. Thanks, Evelyn. I promised Jerry Haley I'd go to the theater with him. 
(Tôi không đi được. Cám ơn Evenlyn. Tôi đã hứa với Jelly Haley, tối đi xem hát với anh ấy!) (Sheldon, 1991, tr.312)

Ví dụ 28: Tại nhà của Connie Garrett, cô Parkermời luật sư Palker-bằng tuổi mình

Connie Garrett: Can I offer you something,Miss Parker? Some tea and cake, perhaps?

(Tôi có thể mời cô một chút gì không, thưa cô Palker? Trà và bánh được chứ?

Parker: No, thanks... I just had lunch.

(Thôi, cám ơn bà ... Tôi vừa ăn trưa xong.) (Sheldon, 1999a, tr.141)

Trong ví dụ 27, Catherine từ chối trực tiếp lời mời của Evenlyn kèm theo lời lý do "I promised Jerry Haley I'd go to the theater with him" (Tôi đã hứa với Jelly Haley, tối đi xem hát với anh ấy!), và ở ví dụ 28 , Parker cũng đưa ra lý do "Ijust had lunch." (Tôi vừa ăn trưa xong.).

Trong các phát ngôn từ chối chứa nhiều thành phần mở rộng thường là có sự tham gia của thành phần mở rộng nêu lí do từ chối. Điều này cũng rất dễ hiểu bởi khi người từ chối muốn lựa chọn một phương tiện làm hài lòng người tham thoại, tỏ thái độ tôn trọng thiện chí với người cùng đối thoại cũng như lí giải cho việc từ chối của mình.

Ví dụ 29: Cuộc thoại giữa Ann và John tại căng tin nhà trường

Ann: May I ask you out for a dinner? (Tôi có thể mời bạn đi ăn tối được không?)

John: Oh, No. It's a pity. I'd love to but my parents from California will visit me this evening. I should cook and have dinner with them at home.

(Ồ, Không. Tiếc quá. Tôi rất muốn đi nhưng tối nay ba mẹ tôi ở California sẽ qua thăm tôi. Tôi nên nấu và ăn tối cùng với họ ở nhà.)

(Trích đoạn trong bộ phim Pretty Woman của đạo diễn Garry Marshall )

Trong ví dụ trên, John đưa ra lời từ chối trực tiếp của mình "No" và kèm theo thành phần mở rộng đưa ra sự nuối tiếc "It's a pity" (Tiếc quá), bày tỏ sự đồng tình với lời mời “I'd love to" (Tôi rất muốn đi) và nêu lý do "I'd love to but my parents from California will visit me this evening. I should cook and have dinner with them at home." (Tôi rất muốn đi nhưng tối nay ba mẹ tôi ở California sẽ qua thăm tôi. Tôi nên nấu và ăn tối cùng với họ ở nhà.). Nói chung, phát ngôn từ chối có nhiều thành phần mở rộng là sự kết hợp của một phát ngôn từ chối với những thành phần mở rộng được người dùng đưa ra nhằm làm hài hòa mối quan hệ với người cùng tham thoại cũng như là cách nói tìm mọi biện pháp nhằm giảm tính đe dọa của phát ngôn từ chối mang lại.

3.8. Chiến lự̛c tù̀ chối bằng cách đưa ra nguyên tắc cá nhân

Đây là CLTC thẳng bằng cách đưa ra nguyên tắc của bản thân để từ chối lời mời. Chiến lược này ít nhiều đe dọa đến thể diện của người mời.

Ví dụ 30: Cuộc thoại giữa ông Edwards và người bạn làm ăn tại văn phòng

Edwards: It's not friendly of you not to have a glass with me.

\section{(Uống với mình một cốc nhé)}

Catherine: No. I tell you, it doesn't agree with me.

(Không. Mình đã bảo cậu rồi. Rượu chè không hợp với mình) (Steinbeck, 2002, tr.75)

Catherine đã từ chối lời mời của người bạn làm ăn bằng cách nêu nguyên tắc cá nhân “it doesn't agree with me." (Rượu chè không hợp với mình). Phát ngôn từ chối này ít nhiều đe dọa đến thể diện của người mời (ông Edwards).

Ví dụ 31: Cuộc thoại giữa một nam giới và nữ đồng nghiệp tại văn phòng

Nam cán bộ: Would you like some tea? (Em dùng trà nhé?)

Jennifer: No, thanks. I never drink tea in the morning.

(Cám ơn anh, Em không bao giờ uống trà vào buổi sáng.) (Trích đoạn trong bộ phim Pretty Woman của đạo diễn Garry Marshall)

Trong ví dụ 31, Jennifer đã từ chối lời mời uống trà của anh bạn đồng nghiệp bằng việc đưa ra nguyên tắc cá nhân "I never drink tea in the morning." (Em không bao giờ uống trà vào buổi sáng) thể hiện dứt khoát từ chối lời mời.

Trong biểu thức từ chối bằng cách đưa ra nguyên tắc cá nhân thường xuất hiện NEVER, NEVER có thể kết hợp với động từ chính $(\mathrm{NEVER}+\mathrm{V})$ hoặc đứng sau động từ tình thái (modal verb + never), trợ động từ chuyên dụng (aux. V + never) nhằm phủ định hoặc bác bỏ.

Ví dụ 32: Cuộc thoại giữa quý ông Montford và quý bà Marchmont tại đại sứ quán Pháp ở London.

Montford: Like some supper, Mrs. Marchmont?

(Mời bà Marchmont dùng bữa đêm.) 
Marchmont: Thank you, Mr. Montford, I never touch supper. But I will sit beside you, and watch you.

(Cám ơn ngài Montford. Tôi không bao giờ ăn đêm. Nhưng tôi sẽ ngồi cùng và nhìn ông ăn) (Wilde, 2000, tr.15)

Ví dụ 33: Cuộc thoại giữa Ken Bailey và Jennifer khi anh lấy ra một chiếc bánh sandwich nhân thịt bò, mời đồng nghiệp nhân dịp cô đến nhà chơi

Ken Bailey: Like some? (Cô có thích ăn một chút không?)

Jennifer: No, thanks. I never eat lunch.

(Cám ơn, tôi không ăn trưa.) (Sheldon, 1999a, tr.35)

Lời từ chối “I never touch supper." (Tôi không bao giờ ăn đêm) của bà Marchmont ở ví dụ 32 và "I never eat lunch" (tôi không ăn trưa.) ở ví dụ 33 thể hiện sự phủ định tuyệt đối lời mời, đồng thời cũng thể hiện những nguyên tắc cá nhân của mình.

\section{Kết luận}

Trên đây là tám chiến lược từ chối trực tiếp lời mời mà người Mỹ thường dùng theo kết quả nghiên cứu mà chúng tôi có được. Có thể thấy, nhìn từ góc độ lịch sự, hành vi từ chối lời mời thường dễ làm tổn thương thể diện dương tính của người mời và người từ chối lời mời vì nó đi ngược lại yêu cầu, nguyện vọng của đối phương, do vậy nên phải từ chối như thế nào để không làm tổn thương đối phương và vẫn đảm bảo duy trì tốt được quan hệ con người với nhau là điều hết sức quan trọng. Qua bài viết này, người viết hi vọng cung cấp cho người đọc những thông tin liên quan đến các chiến lược từ chối trực tiếp lời mời mà người Mỹ ưa dùng từ đó áp dụng trong giao tiếp để đạt được hiệu quả cao nhất.

\section{TÀI LIẸU THAM KHẢO}

Beebe, L. M., Takahashi, T., \& Uliss-Weltz, R. (1990), Pragmatics transfer in ESL refusals, Newbury House, New York.

Brown P. \& Levinson S. (1978), Universals in language usage: Politeness phenomena, Cambridge University Press.

Hoàng Phê (2006), Tù điển tiếng Việt, NXB Đà Nẵng, Đà Nẵng.

Searle, J. R. (1969), Speech Acts: An Essay in the Philosophy of Language, Cambridge University Press.

Miranda, S. (2003), Oxford Wordpower, Oxford University Press, England.

\section{NGUỒN NGŨ๋ LIỆ}

Adeline Catherine Anderson (1996), Annie's song, An Imprint of Harper Collins Publishers, New York.

Arthur Conan Doyle (1986), Sherlock Homes Complete, Bantam Classics.

Charlotte Bronte (2003), Jane eyes, Penguin.

Colleen McCullough (1977), The Thornbird, Harper \& Row; Book Club edition.

Erich Segal (1970), Love story, Coronet Books, Hodder Paperbacks Ltd.

John (2000), The Brethen, Arrow Books, Grisham.

John Steinbeck (2002), East of Eden, Penguin Books.

Jojo Moyes (2012), Me before you, Pamela Dorman Books.

Margaret Mitchell. (1999). Gone with the wind, Grand Central Publishing.

Oscar Wilde. (2000)., An Ideal Husband, Dover Publications Inc, London.

Richards, J. C., Hull, J. and Protor S. (2004), New Interchange, Cambridge University Press.

Sidney Sheldon (1976), A Stranger in the Mirror, The Macmillan company of india ltd.

Sidney Sheldon (1985a), If tomorrow comes, HarperCollins Publishers.

Sidney Sheldon (1985b), The Naked face, Grand Central Publishing.

Sidney Sheldon (1991), Memories of Midnight, Warner Books.

Sidney Sheldon (1995a), Nothing Lasts forever, Grand Central Publishing.

Sidney Sheldon (1995b), The Stars Shine Down, HarperCollins Publishers.

Sidney Sheldon (1999a), Rage of Angles, HarperCollins Publishers.

Sidney Sheldon (1999b), Tell Me Your Dreams, Vision.

Sidney Sheldon (2001), The sky is falling, Time Warner.

Stephenie Meyer (2006), New Moon, Little, Brown and Company, New York

Tư liệu truyền hình (Trích đoạn trong bộ phim Pretty Woman của đạo diễn Garry Marshall) 


\section{Some strategies to directly reject American invitations}

\section{Pham Tuan Doanh}

\section{Article info}

Recieved:

15/3/2019

Accepted:

$10 / 6 / 2019$

Keywords:

refusal acts; refusal strategies; invitations; direct refusal strategies, refusal acts of invitations

\begin{abstract}
Refusals, like other acts, appear in all languages. It is used to express the acceptance of change according to the suggestions (such as requests, offers, invitations, suggestions etc) in conversations. Due to the influence of some factors such as social status, gender, age ..., when rejecting an invitation, American can choose direct refusal strategies or indirect refusal ones. In this article, the author presents a brief description of the results that we have obtained when studying some direct refusal strategies of invitations of American.
\end{abstract}

